\title{
Cultural Capital and Leisure Performances as Aids to Disaster Recovery: Niigata Bull Pushing and New Orleans' Carnival
}

\author{
Jon Griffin Donlon
}

\begin{abstract}
There is little question that leisure performances such as the Carnival of New Orleans [Mardi Gras], and the bull fight or bull-pushing festival in Niigata prefecture, Japan, often contribute to knitting together local community, reflect group identity and values, and act to enforce continuity of culture. At the same time these leisure performances foster so-called "hybridity." They are, in effect, engines of continuity and change. As a result, these festive settings may be seen as liminal zones offering both insulation from change and mechanisms through which cultural change may be absorbed, altered, negotiated and otherwise "handled." This paper focuses on discussing how cultural performances such as these festive settings often function to create social capital (good will) and, especially in times of disaster, "discharge" much of this capital both to sustain a continuity of tradition and to negotiate with the "new," or emerging circumstances. It chiefly mentions research on two regions, explaining the role of the relevant leisure performances and establishing a little of each community's cultural past. I will discuss how, in both regions, there was strong controversy (involving the bull pushing festival in Niigata and Mardi Gras in New Orleans) circulating about the disposition of scarce resources.
\end{abstract}

Index Terms-Bull fighting, carnival, cultural, capital, Japan, leisure, performance, mardi gras.

\section{INTRODUCTION}

Fieldwork identified remarkable similarities in spite of varied cultural origins and nominal geographic locations at such ephemeral events as camel wrestling in Turkey, "bull pushing" festivals in Japan, and Mardi Gras in the USA. At the same time, these social occasions generally also possessed great differences, marking them as intimately tied to local culture. For example, they strongly vary how they bring about the "playful" imaginative reality which is the core feature of each event. None-the-less, creation of good will is always a goal and is thus a unifying characteristic.

This paper focuses on the bull fighting or bull-pushing festival in Niigata, Japan, and carnival in New Orleans, USA, with special attention to effects of disaster including the impact of hurricane Katrina in 2005 (according to Wikipedia, "the costliest natural disaster, as well as one of the five deadliest hurricanes, in the history of the United States") and the destructive earth quake in Niigata prefecture. Festive episodes embracing the carnivalesque, such as New Orleans's Mardi Gras are, at their most quotidian, functions of the imagination. These festivals exist not only as temporal

Manuscript received May 23, 2013; revised July 29, 2013

Jon Griffin Donlon is with the Sport and Leisure Management, Tokai University, 1117 Kitakaname, Hiratsuka, Kanagawa, 259-1292 Japan (e-mail: jhdonlon@hotmail.com). inventions, but as ephemeral and friable construction of the participants.

New Orleans' Mardi Gras and the Japanese bull fighting or pushing festival in Nagaoka City, Yamakoshi, Niigata, offer especially good "test beds" for discussing the nature of ephemerality and social capital. Immediately after each disaster, a volatile and quite public discourse developed about the "utility" of both carnival and the bull-pushing festival. In addition, soon but not quite immediately after Katrina in New Orleans, a commercial drama was developed portraying the stricken city. A central element in this virtual portrayal of New Orleans was the contestation about hosting Mardi Gras during the recovery stage; this drama functioned as independent corroboration of the presence of this contest for meaning regarding these festivals.

Half the globe away from New Orleans' Carnival, around Niigata, Japan, which traditionally hosts a uniquely Asian "bull pushing" event, very similar discourse took place following a destructive set of powerful earthquakes (although no commercial drama was developed to exploit the suffering of the Japanese in that region.)

Although these kinds of leisure settings, so-called ephemeral festivals which are entirely temporary or non-substantial events undertaken with no necessary intention of continuity are playful, they are not "work empty." It's a laborious procedure to costume and provide hospitality or rear and tend to livestock. Such community-building leisure performances are unlike say, repetitive seasons of football for which a stadium might be built, and which acknowledge the reality of a between the seasons episodic practice environment and a ladder of developmental growth from junior players toward professionals. And it's tedious, often "hard" work keeping the real world at bay even temporarily.

At the onset, it might be mentioned that, as is perhaps obvious, in spite of regional and often quite unique or idiosyncratic means of creating festive events, generally similar patterns of solution finding often seem to be present. After all, biology drives certain needs while culture stimulates other wants which are addressed.

In exactly the same way that fundamental structural forms seem to be apparent, cross-culturally in the presentation of often quite varied and certainly geographically widely distributed ephemeral festival events, other similarities exist. Following the significant earthquake destruction in the region around Niigata, Japan, a local discussion was held about cancelling the otherwise rare bull-pushing festival at Nagaoka City until the villages were "rebuilt." The affirmative voice argued for a sustained application of all resources in one direction: the bricks \& mortar rebuild effort. 
The contrarian or voice in defense of the festival claimed benefits based on the event's much-needed "community building" outcomes. In the end, the bull pushing festival took place.

\section{CARnival On the American Gulf COAST}

Although carnival has roots extending back to the late 1800s in the U.S. and the Middle Ages in Europe, Treme, a dramatic series which popularized the festival and publicized it, was developed as a commercial series by David Simon and Eric Overmyer, very recently. They poached its name from the chronically low-income/high-local culture Tremé neighborhood of the Big Easy; the City That Care Forgot until 2005.

The drama begins a few months after hurricane Katrina. Residents of New Orleans: artists, academics, chefs \& cooks, musicians, Mardi Gras Indians, workers and the under-employed of Greater New Orleans begin rebuilding their lives, their homes and their special culture as the city itself is rebuilt after the hurricane. or, more properly, the flooding and inundation.

Because so-called ephemeral festivals lack the bricks-and-mortar of more literally concrete physical or social constructions it is on occasion possible for naive people to trivialize their importance or their difficulty. And, being ephemeral, these festive events do lack the kind of tangibility which tends toward durability and permanence. It's possible this explains the great divide which at times develops: struck by disaster, should a region invest in the tangible or spend on securing or saving the future of easily lost cultural matter?

Treme, the dramatic series, premiered on April 11, 2010 HBO, airing an 80-minute pilot, point for its 10 episode season. Later HBO renewed the series for another season which premiered in April, 2011; finally, Treme was renewed for a third season.

A strong motif in the series involves one character very eagerly awaiting Mardi Gras, in the dramatic, HBO reality attaching his hopes to the symbolism of renewal embedded in each year's carnival (this character's feeling of loss of "place" standing in for an overall sense of collapse of community after a disaster). Unfulfilled, his feeling of community not replenished in spite of the vitality of festival, he jumps from the famous Algiers's ferry. Fittingly, he is lost, as the city was lost, under the dark water. Some viewers might imagine that this kind of intensity is "over the top" in terms of attachment to local markers.

\section{BULL "FIGHTING" OR PUSHING IN JAPAN}

According to Hirokazu Ishii in his paper, Bull Fighting: Tradition and Acculturation, "bullfighting in earlier times was a simple pastime that farmers enjoyed by themselves" [1] The scholar explains that the sport developed as a rural undertaking but, as it currently survives, it often owes a lot to being of interest to tourists, who visit rural settings to "consume tradition." At first, the farmers "would bring their bulls to a spot between hills, a dry river bed, or the like, where they could enjoy this activity. With the objective of easing the economic burden on the bull owners, farmers began charging "fight money"'. As we can presume, there was also the usual element of prestige associated with exhibition of prowess and the value of display, which comes with performance. Eventually, as Hirokazu Ishii describes in his history, "bullfighting became a rather popular sport, similar to Ozumo (professional sumo wrestling)". And, in many ways, these festivals are representative of the larger, host, social environment

In Bull Fighting: Tradition and Acculturation, Hirokazu Ishii further notes, writing directly of the special species of Japanese bullfighting, that "today bullfighting still survives in Ojiya City and Yamakishi Village in Niigata Prefecture, Okinoshima, Tokunoshima, Okinawa, and the Nanyo district in Ehime Prefecture". Our discussion involves Japanese bullfighting or pushing) in the Niigata area.

Meanwhile, in Jutai (Congestion, 1991) a film which contrasts the stresses of urban life and the tranquility of "home," or the birth village, the Fujis' family trip home for Obon "the modern urban-industrialized lifestyle is experienced with a twinge of regret and sense of loss, while remote areas become idyllic representations of a more pristine way of life, less corrupted by industrial dehumanization, urban anomie, or Western influences" [2]. The researcher goes on to suggest that the "desire to emulate tradition and a lost rural lifestyle reveals a contemporary quest for community and collective identity". The popularity of these events seems to support this suggestion.

The bull pushing example from the festival in Nagaoka City, Yamakoshi, Niigata prefecture, Japan, is an event which is very special in the lives of the people of the region and far from common place. In spite of being strongly identified with this particular region, as a mechanism to develop "good will" this quite unique event becomes representative of ephemeral festivals. I suggest that traditional festive settings, such as the bull pushing festival (which may be called bull fighting by some), and carnival in New Orleans provide a variety of positive resources to the community, most of which shelter under the rubric of social capital - "good will." All such "good will" benefits provide a measurable increase in local ability to respond and/or react to (or manage the risk of) predictable local hazards.

\section{RECOVERY FROM DISASTER AND SOCIAL CAPITAL}

An important discussion of the topic by Nakagawa \& Shaw points out that "natural events like earthquakes, floods, cyclones, or droughts" and, similarly damaging man-made phenomena, "occur within the various processes of nature, however these events become disasters when they affect human lives and livelihoods" [3]. While it is perhaps less clear that, as they also claim, "in recent years, natural disasters have changed their characteristics and the risk of being affected by natural disasters has significantly increased...". [Their reference about numbers of major events having increased dramatically "from the 1960s, and in the 1990s, the number almost doubled from the previous decade" based on Data Book 2002 may be a reflection of demographic shift or housing pattern effect more than inherency of risk related to natural disaster [4]-[5]. It is not really germane if risk from legitimate hazard, natural or 
man-made, has increased. What is on point here is that significant research seems to point to the benefit of so-called "social capital," a reservoir of good-will, stiffening the will of the disaster victims in the recovery period.

Indeed, recently, community involvement has increasingly gained traction with researchers [6]-[9]. I can say that all of my research in the Gulf area of Louisiana after Hurricanes (typhoons) Katrina and Rita in 2005 struck that region, and my later research near Niigata, Japan, following devastation from earth quake, underline the importance of community involvement. This all shades in the general sense of the value specialists seem to have found in incorporating disaster management into the holistic engagement with communities. As Maskrey has noted, disaster management might best be thought of as being seamlessly folded into the socioeconomic activities oflocal people and not as a free-standing, single activity [10].

According to the conclusion of the Preliminary Report: Mid-Niigata Prefecture Earthquake (Preliminary report on damage caused by Mid-Niigata Prefecture Earthquake on October 23, 2004), "it must be remembered that the earthquake-stricken region had been affected by a series of typhoons immediately before the earthquake. In this respect, the event can be compared with the 1923 Great Kanto Earthquake, where damage was caused not only by the earthquake but also by firestorms whipped up by strong typhoon winds. The continual rain experienced in the stricken areas of Niigata in November will turn to sleety rain and then snow as the cold season approaches. Some places will receive several meters of snow" [11]. It is necessary to consider all impacts and all outcomes or results.

Nakagawa \& Shaw explain quite pointedly that "earthquakes [meaning disasters] affect all, including rich, middle-class and poor. When they destroy an urban area, massive re-planning of the city is required. Thus, the recovery process is a learning exercise on what is safe and sustainable for the community". It's obvious that national, provincial, and local authorities place enormous emphasis on resisting initial impact, reducing vulnerability, and creating more robust sustainability in their rehabilitation [12]. None the less, when it comes to disaster recovery programs, some communities snap back faster while exhibiting more satisfyingly humanistic recovery programs.

\section{Conflict Between Rebuilding the Place and the SPACE}

Following disaster in Niigata, Japan and in the United States in New Orleans, there was a good deal of discussion about "splitting off" a portion of the available scarce resource in order to participate in the local traditional festivals (bull pushing in Japan, Mardi Gras along the US Gulf Coast). In each case some local factions were for, and some against re-instituting the events, and some were for a close focus only on the "rebuilding" effort. Discussion with people in the small, rural Japanese community struck by disaster stemming from earthquake uncovers at least two "factions." Part of the community urged $100 \%$ focus on rebuilding the basic infrastructure. A second voice suggested re-engaging the folk festival including bull pushing (for which the area was increasingly building a cultural tourism income). In New
Orleans, following the disastrous strike by hurricane Katrina, there was also a suggestion of canceling the annual Mardi Gras festival. The local folk were similarly of two voices.

Carnival has been cancelled only a few times since1872 - once after the Civil War, a few times in WW II, then for the 1979 police strike. According to the record now, "some ---actually many-had argued Katrina was such an extraordinary event that the city should cancel its pre-Lenten celebration [Mardi Gras]. After all, the city was broke, and holding a big municipal party cost millions in police overtime and other services" [13]. In the end Carnival was held, and, as we may have predicted, the value of building community was far greater than the costs of a few overtime employees.

These events are, in their specifics, very, very different. However, in general contours the two traditional events share formal structures. The two festivals I am looking at - the bull pushing festival in Japan and the carnival in New Orleans - provide the stage upon which traditional values are privileged, and inculcated. Each is a structural mechanism for transferring cultural matter across trans-generational units, and so on. Each gives great value by offering cherished and important primary and secondary (or latent) cultural and social functions.

\section{ACKNOWLEDGEMENTS}

The author wishes to acknowledge the kind and helpful assistance of his partner, Dr. J.H. Donlon, and his colleagues and co-workers in the Department of Sport and Leisure Management, School of Physical Education, Tokai University, Japan, for their support and superb example. I also wish to thank my social circle for their enormously important contribution to this and all of my work via vital and energetic conversation and discussion.

\section{REFERENCES}

[1] H. Ishii, "Bull fighting: tradition and acculturation," International Journal of Sport and Health Sciences, vol. 4, pp. 152-160, 2006.

[2] M. Creighton, "The marketing of tradition and nostalgia in the Japanese travel industry," Ethnology, vol. 36, no. 3, pp. 239-254, 1997.

[3] Y. Nakagawa and R. Shaw, "Social capital: a missing link to disaster recovery," International Journal of Mass Emergencies and Disasters, vol. 22, no. 1, pp. 5- 34, 2004.

[4] S. George, The Debt Boomerang: How Third World Debt Harms Us All, London: Pluto Press, 1992.

[5] L. Brown and L. Starke, State of the World 1996: a Worldwatch Institute Report on Progress Toward a Sustainable Society, New York: W.W. Norton \& Company, 1996.

[6] P. Blaikie, T. Cannon, I. Davis, and B. Wisner, At Risk: Natural Hazards, People's Vulnerability, and Disasters, London: Routledge, 1994.

[7] J. Twigg and M. Bhatt, Understanding Vulnerability: South Asian Perspectives, London: ITDG, 1998.

[8] D. S. Mileti, Disasters by Design, Washington D.C: Joseph Henry Press, 2001.

[9] R. Shaw and K. Okazaki, Sustainability in grass-roots initiatives: focus on community based disaster management, Kobe: UNCRD, 2003.

[10] A. Maskrey, Disaster Mitigation-A Community Based Approach, London: Oxfam, 1989.

[11] Data book on Asian natural disasters in the $20^{\text {th }}$ century, natural disasters in India, Data Book, Kobe: Asian Disaster Reduction Center, 2002.

[12] R. Shaw, M. Gupta, and A. Sharma, "Community recovery and its sustainability: lessons from Gujarat earthquake of India," Australian Journal of Emergency Management, vol. 18, no. 2, pp. 28-34, 2003.

[13] C. Cooper and R. Block, "Disaster, hurricane katrina and the failure of homeland security," Time Books, New York, 2006, pp. 284. 
Jon Griffin Donlon is a Ph.D who is the author of Bayou Country Bloodsport: The Culture of Cockfighting in Southern Louisiana (McFarland \& Co., 2012). He left his Louisiana home to pursue graduate work at the University of Illinois, Illinois, USA. He earned a Ph.D. in the Department of Leisure Studies, specializing in controversial leisure with an emphasis on cultural tourism. In the ensuing decades, Donlon has become an acknowledged authority on the petit monde: blood sport, (of course including cockfighting), sex work and its orbit of suspect entertainment, risky recreation and similar, to some, unsavory pass times. Most recently he's been working internationally on the relationship of festive settings and recovery from disasters. A professor at Tokai University in Tokyo whose first degree was in the fine arts, he brings into being illustrations in support of his research as well as creating drawings, painting, and video material fictively referencing his life experiences. Today, because of this unique expertise in controversial leisure, the scholar remains active as an artist, consultant teacher, and special expert within the legal system. Professor Donlon is currently contemplating a move from Asia to North America and is beginning to re-emphasize his research into cultural tourism and perceptions of the real and "the fake." He is currently hard at work on a set of thirteen lectures based on the leisure studies canon. 